\title{
Disposal of Belt Filtered Tailings - Skorpion Zinc Case Study: Feasibility, Design and Early Operation
}

\author{
A.M. Copeland, K.A. Lyell Anglo Technical Division, South Africa \\ P. van Greunen Skorpion Zinc Mine, Namibia
}

\section{INTRODUCTION}

Skorpion Zinc Mine comprises an opencast mine and refinery and is located in the south west of Namibia in a very arid area, with desert sand dunes to the west and rugged mountains to the east. The refinery began operating in mid 2003 treating an oxide orebody to recover zinc by means of a leaching, solvent extraction and electro-winning process. The tailings produced from the leaching process is belt filtered to recover soluble zinc, justifying the expense of filtration. The filter cake is a fine grained material with significant clay and mica fractions and has a high average moisture content of $40 \%$ (water mass/total mass). While filtration achieved key objectives of recovering soluble zinc contained in residue and minimising water consumption, the transportation and disposal of the tailings posed technical challenges. This case study aims to cover a 7 year period including the feasibility study, design and early operating period, highlighting issues and decisions associated with each phase of the project.

\section{CONTENT OF CASE STUDY}

\subsection{Background}

The zinc deposit is located on the edge of a diamond protection zone of Namibia known as the Sperrgebied, $90 \mathrm{~km}$ inland from the Atlantic Ocean. Public access to this area has been denied for more than 90 years. An environmental assessment report produced in 1998 described the mine site as "pristine desert" and highly sensitive to human disturbance. The climate is extremely arid with annual average rainfall $<20 \mathrm{~mm}$ with sparse flora relying on fog and dew for moisture. Sand dunes lie to the west of the mine deposited by the prevailing moderate to strong southerly and less frequent strong north-easterly winds. Groundwater is deep, low yield and poor quality. The Orange River that flows along the border between Namibia and South Africa provides the only viable source of industrial water and is strictly controlled.

A conceptual disposal study (Jones and Wagener Consulting Engineers (1998)) had been undertaken for the former client (Reunion Mining) and had considered a range of alternatives. Initially it was recommended that the filter cake be re-slurried and pumped to an impoundment facility with walls formed with overburden waste stripped from the pit. A subsequent study proposed that the tailings be transported by conveyor to a pre-built embankment on which a mobile tripper and stacker would be installed to deposit the tailings. 
This change from hydraulic to conveyor transportation of the tailings exposed the dilemma of receiving a filter cake at $40 \%$ moisture content (with a consistency similar to potters clay) and then having to convey it a few kilometres with a suitable disposal system. Conventional wisdom would be to dispose hydraulically.

\section{$2.2 \quad$ Feasibility study}

A trade-off study of six disposal options was carried out in 1999-2000 (Anglo American Technical Services (2000)). This work began with testwork on pilot plant samples that provided the necessary information to investigate disposal options. A risk and decision matrix process was used to select the best system.

\subsection{Design of selected system}

The conveying and stacking option was identified as the preferred system. A stacker conveyor on a starter embankment was designed that would advance across the tailings by pivoting about a transfer point. The design had to assess the risks of tailings conveyability at variable moisture contents and the advancement of the stacker over the filter cake.

\section{$2.4 \quad$ Tailings disposal operation}

The tailings conveyor and stacker disposal system was built and has been operating for just over 2 years. In this period it has been possible to gain a better understanding of the tailings behaviour during belt filtration, conveying and disposal. While the system as a whole has operated well, some changes have been necessary, and this paper highlights aspects that need to be considered in similar systems.

\section{FEASIBILITY STUDY}

The purpose of the feasibility study was to determine the most appropriate tailings transportation and disposal method, and the most suitable site for life of mine. A pilot plant was constructed to prove the zinc recovery process. This provided the opportunity to obtain tailings samples off a small belt filter.

\subsection{Production data}

The following production data was provided:

- Tailings dry tonnage production rate $=170 \mathrm{t} / \mathrm{hr}$ (average), $210 \mathrm{t} / \mathrm{hr}$ (peak).

- $\quad$ Mine life $=14$ years.

This translated to a tailings design tonnage of $116280 \mathrm{t} /$ month and $20 \mathrm{Mt}$ for life of mine. It was expected that the average tailings moisture content after filtration would be $40 \%$.

\subsection{Testwork undertaken and key results}

The filter cake samples were subjected to a number of geotechnical, rheology and materials handling tests. 
The most important tailings geotechnical parameters obtained from these tests included:

- Low presence of sulphides and high buffering capacity (low acid generation potential).

- The mineralogy comprises predominantly silica and quartz minerals with significant mica content and an average specific gravity of 2.7 to 2.8 .

- The grading is fine with $100 \%<0.3 \mathrm{~mm}, 75 \%<0.075 \mathrm{~mm}$ and $13 \%$ clay, and a plasticity index of 8 .

- An average permeability of $4 \times 10^{-8} \mathrm{~m} / \mathrm{s}$, coefficient of consolidation of 6 to $45 \mathrm{~m}^{2} / \mathrm{yr}$, and friction angle of 33 degrees.

- Moisture content (gravimetric) ranged from 38 to $44 \%$ depending on ore, flocculant and filtration efficiency.

- Liquid limit ranged from 36 to 50\% indicating that the cake is saturated to over-saturated, and the linear shrinkage from 3 to $6 \%$.

The significant clay and mica fractions in the tailings are consistent with the low permeability and consolidation properties and high saturation moisture content. Consolidation, beaching and bearing capacity of the tailings were identified as potential problems due to the inability of the cake to release water.

The most important rheological parameters obtained from the testwork included:

- The slurry behaved as a non-Newtonian and non-settling slurry mixture over a density range of 1.39 to $1.55 \mathrm{t} / \mathrm{m}^{3}$ (cake density $=1.63 \mathrm{t} / \mathrm{m}^{3}$ at $40 \%$ moisture content).

- The paste slurry requires positive displacement pumps for densities between 1.50 and $1.55 \mathrm{t} / \mathrm{m}^{3}$ (yield stress of 65 to $175 \mathrm{~Pa})$.

- The limit for centrifugal pumping would be a slurry density of between 1.46 and $1.50 \mathrm{t} / \mathrm{m}^{3}$ (yield stress of 25 to $65 \mathrm{~Pa}$ ).

This information provided the basis for considering options of reslurrying the cake for pipeline transportation, as well as water consumption implications.

The most important materials handling parameters obtained from the testwork included:

- The tailings had a minimum adsorbed moisture content of $6 \%$ (difference in air and oven drying).

- The cake ( $40 \%$ moisture content) did not ready flow out of a slump cone and exhibited minimal slump ( $<5 \mathrm{~mm}$ of ASTM standard cone) and bleed water even with vibration.

- The cake does not have good flow properties and will require very steep chutes or bin slope angles coupled with low friction liners due to its high shear strength (adhesion).

The potential for the tailings cake to stick to conveyor belting, chutes, bins and truck bowls was identified as high and would require special design considerations. Additional dewatering by pneumatic drying of the 
cake was proposed to improve its handling properties. Preliminary investigations did not find this to be viable.

\subsection{Site selection}

Based on condemnation drilling, wind directions, pit, plant and waste rock dump positions, environmental factors and other boundary constraints, a site to the north of the waste rock dump was singled out as the most suitable site. It is good practice to separate mine waste and tailings disposal for environmental and future retreatment reasons. However some co-disposal options were considered in the feasibility study.

\subsection{Disposal systems}

Six disposal systems were conceived and can be categorised into separate and co-disposal options, and wet and "dry" disposal options. Dry disposal refers to the filter cake, whilst wet disposal refers to slurry or paste. For each of these systems, conceptual designs, drawings and costs (capital, operating and closure) were generated. Table 1 summarises the disposal options while diagrammatic configurations of the three main systems are captured on Figure 1.

Table 1 Summary of disposal systems

\begin{tabular}{|l|l|l|}
\hline No. & \multicolumn{1}{|c|}{ Transportation Method Dry - co-disposal } \\
\hline \multicolumn{3}{|c|}{ Disposal Method } \\
\hline 1. & $\begin{array}{l}\text { Convey cake to storage bins near waste rock dump. } \\
\text { Load trucks to haul to waste rock dump }\end{array}$ & $\begin{array}{l}\text { Tip cake and mix with waste rock and doze to } \\
\text { form dump (tailings:waste = 1.0:4.5) }\end{array}$ \\
\hline 2. & $\begin{array}{l}\text { Convey cake to stockpile near waste rock dump. } \\
\text { Load trucks and haul to waste rock dump }\end{array}$ & Same as for 1 \\
\hline \multicolumn{3}{|c|}{ Dry - separate disposal } \\
\hline 3. & $\begin{array}{l}\text { Convey cake to 40m high waste rock embankment } \\
\text { on which stacker conveyor system installed }\end{array}$ & $\begin{array}{l}\text { Spreader deposits over edge. Dozer forms } \\
\text { platform. Stacker advanced over tailings }\end{array}$ \\
\hline \multicolumn{3}{|c|}{ Wet - separate disposal } \\
\hline 4. & $\begin{array}{l}\text { Re-slurry cake at the plant to high density slurry } \\
\left(1.40-1.45 \mathrm{t} / \mathrm{m}^{3}\right) \text { and pump to impoundment }\end{array}$ & $\begin{array}{l}\text { Open-end slurry from 40 m high waste rock } \\
\text { impoundment walls to maintain central pool }\end{array}$ \\
\hline 5. & $\begin{array}{l}\text { Convey cake to site, re-slurry to high density (1.40 } \\
\left.-1.45 \mathrm{t} / \mathrm{m}^{3}\right) \text { and pump into impoundment }\end{array}$ & Same as for 4 \\
\hline 6. & $\begin{array}{l}\text { Re-slurry cake at the plant to a paste (1.45 to } 1.55 \\
\left.\mathrm{t} / \mathrm{m}^{3}\right) \text { and pump to impoundment }\end{array}$ & $\begin{array}{l}\text { Open-end paste from one 40 } \mathrm{m} \text { high waste rock } \\
\text { wall towards lower boundary walls }\end{array}$ \\
\hline
\end{tabular}




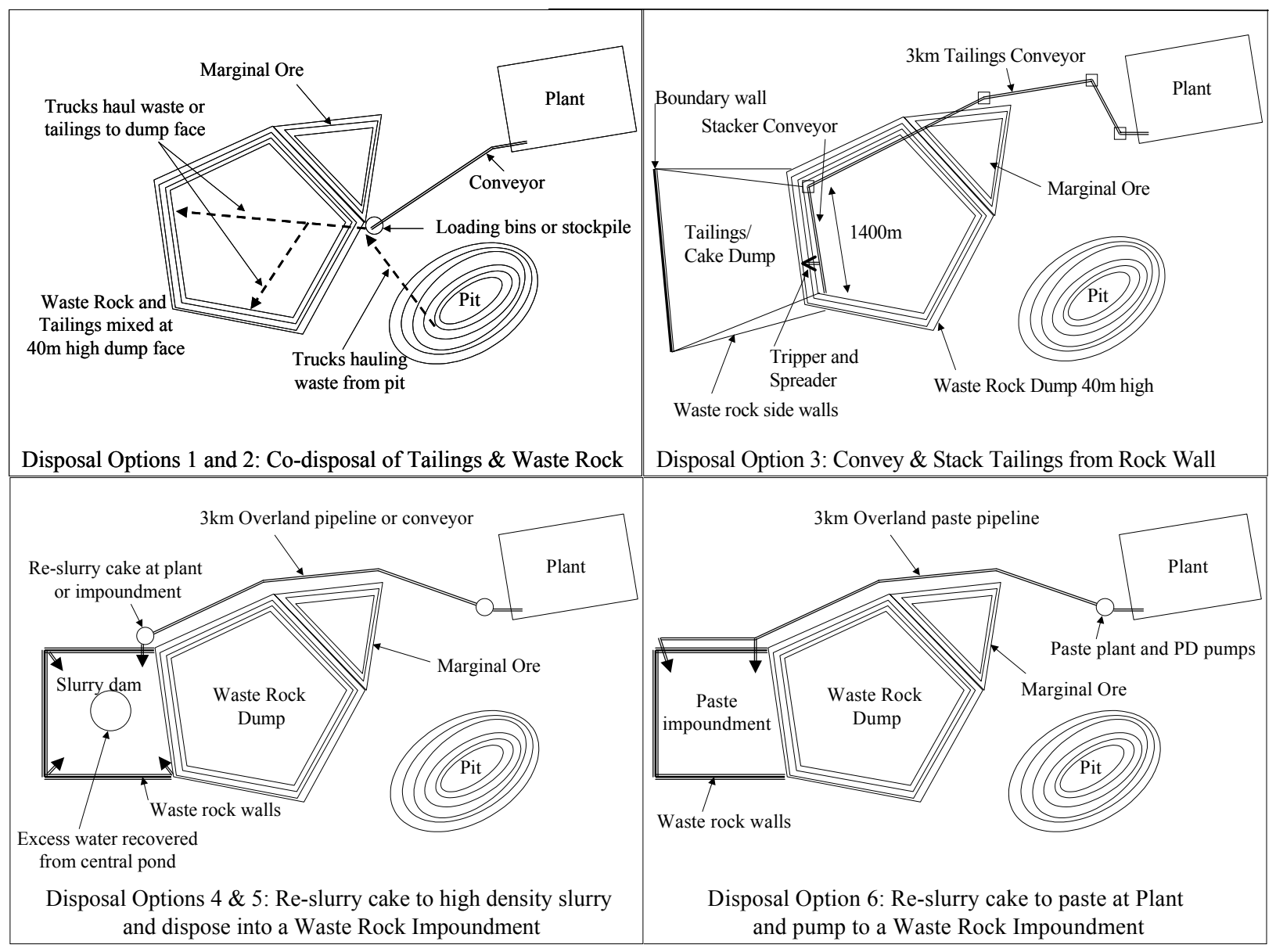

\section{Figure 1 Conceptual layouts of tailings disposal systems}

A summary of the NPV costs for the disposal systems is given in Table 2 .

Table 2 Summary of disposal system costs (Rands - millions)

\begin{tabular}{|c|c|c|c|c|c|}
\hline System & Capital Cost & Operating Cost & Closure Costs & Total Costs & R/t \\
\hline 1 & 14.8 & 30.4 & Incl. in rock dump & 45.2 & 2.28 \\
\hline 2 & 10.9 & 55.9 & Incl. in rock dump & 66.9 & 3.38 \\
\hline 3 & 17.7 & 35.2 & 0.5 & 53.4 & 2.70 \\
\hline 4 & 16.7 & 41.1 & 0.2 & 58.0 & 2.93 \\
\hline 5 & 24.1 & 41.1 & 0.2 & 65.4 & 3.31 \\
\hline 6 & 24.4 & 59.7 & 0.4 & 84.5 & 4.27 \\
\hline
\end{tabular}

A recognised evaluation process, Multiple Account Analysis, MMA (Multiple Accounts Analysis (1999)) was used to compare each of the systems. It breaks the systems down into accounts (technical, environmental, economic and socio-economic), sub-accounts and risk indicators. A technical sub-account in this case would be tailings transportation, with an associated risk indicator such as length of conveyor or pipeline. A maximum value of 9 is assigned to the shortest distance and the others a proportionately lower value. Through a transparent ranking and weighting process for each indicator, sub-account and account, an aggregated score is generated for each system. The results are summarised in the Table 3. 
Table 3 Summary of MAA decision process results

\begin{tabular}{|l|c|c|c|c|c|c|}
\hline \multirow{2}{*}{ Accounts } & \multicolumn{7}{|c|}{ Tailings Disposal System - Scores } \\
\cline { 2 - 7 } & $\mathbf{1}$ & $\mathbf{2}$ & $\mathbf{3}$ & $\mathbf{4}$ & $\mathbf{5}$ & $\mathbf{6}$ \\
\hline Technical & 4.68 & 5.61 & 6.02 & 5.58 & 5.08 & 6.45 \\
\hline Environmental & 5.96 & 5.96 & 8.15 & 7.21 & 7.33 & 7.96 \\
\hline Economic & 8.41 & 7.24 & 7.46 & 4.96 & 4.34 & 3.52 \\
\hline Socio-Economic & 6.59 & 6.59 & 8.13 & 8.49 & 8.25 & 8.63 \\
\hline Final Aggregated Account Score & $\mathbf{6 . 2 7}$ & $\mathbf{6 . 2 7}$ & $\mathbf{7 . 1 2}$ & $\mathbf{5 . 9 9}$ & $\mathbf{5 . 6 2}$ & $\mathbf{6 . 0 6}$ \\
\hline
\end{tabular}

System 3 scored the highest out of a maximum score of 9 and therefore rated the best overall system, despite not being the best economic system. Since most stakeholders had given their input to the process, the outcome was accepted. This integrated assessment approach is recommended as a decision making tool in such trade-off studies. Risks for each system can be proportionately assigned, and only fatal flaws can rule out a system.

The feasibility study concluded that the conveyor and stacker disposal system should be designed and implemented, however, attention would need to be given to:

- The behaviour of the cake on the conveyor belts and transfer points (variable moisture content).

- The planning of conveyor moves and waste rock wall construction.

\section{DESIGN OF CONVEYOR STACKER SYSTEM}

\subsection{Conveyor system}

The cake is dropped onto a common collection conveyor from the end of each filtration unit. This conveyor can either transfer the cake to an emergency conveyor if the cake is out of specification (16 hr capacity stockpile) or onto the first leg of the overland conveyor. A reload facility on the overland conveyor allows for removal of the stockpiled material. The first leg transfers the cake to the main $3 \mathrm{~km}$ long overland conveyor which runs to the disposal site. The cake normally reports to the stacker conveyor but can be diverted to the by-pass conveyor if required. From the stacker conveyor the cake transfers to a $25 \mathrm{~m}$ long spreader conveyor which is mounted on a tripper that runs the length of the dump face.

The stacker conveyor system conceived in the feasibility study (see Figure 1) was based on a face advancing conveyor installed on top of a waste rock wall averaging $40 \mathrm{~m}$ above ground level. The rock wall and stacker conveyor was $1400 \mathrm{~m}$ long. It was discovered that there would be inadequate waste rock to form this length of wall by the time the conveyor needed to be commissioned. Initially a shorter wall and conveyor was considered that would be extended in line with waste rock and tailings production. However since this was not known to be a proven system and may require extensive use of the by-pass node, it was not accepted. 


\subsection{Stacker conveyor type}

A pivot advancing stacker conveyor, rotating about the transfer point was considered. Such a system was known to be working successfully on another Anglo Base Metals mine, and was selected for design. This requires deposition of a wedge of tailings. Less waste rock was required initially and could be accommodated within the open pit waste stripping programme. Figure 2 shows the revised layout of this $\mathrm{s}$ cheme with a $550 \mathrm{~m}$ long waste rock wall along the side of a hill on which the stacker conveyor would be installed. The figure shows the three phased development of the site, with two relocations of the stacker to fill the life of mine area designated for the tailings. This required the construction of new permanent conveyors and transfer points during the dump's life, preceded by construction of the waste rock walls.

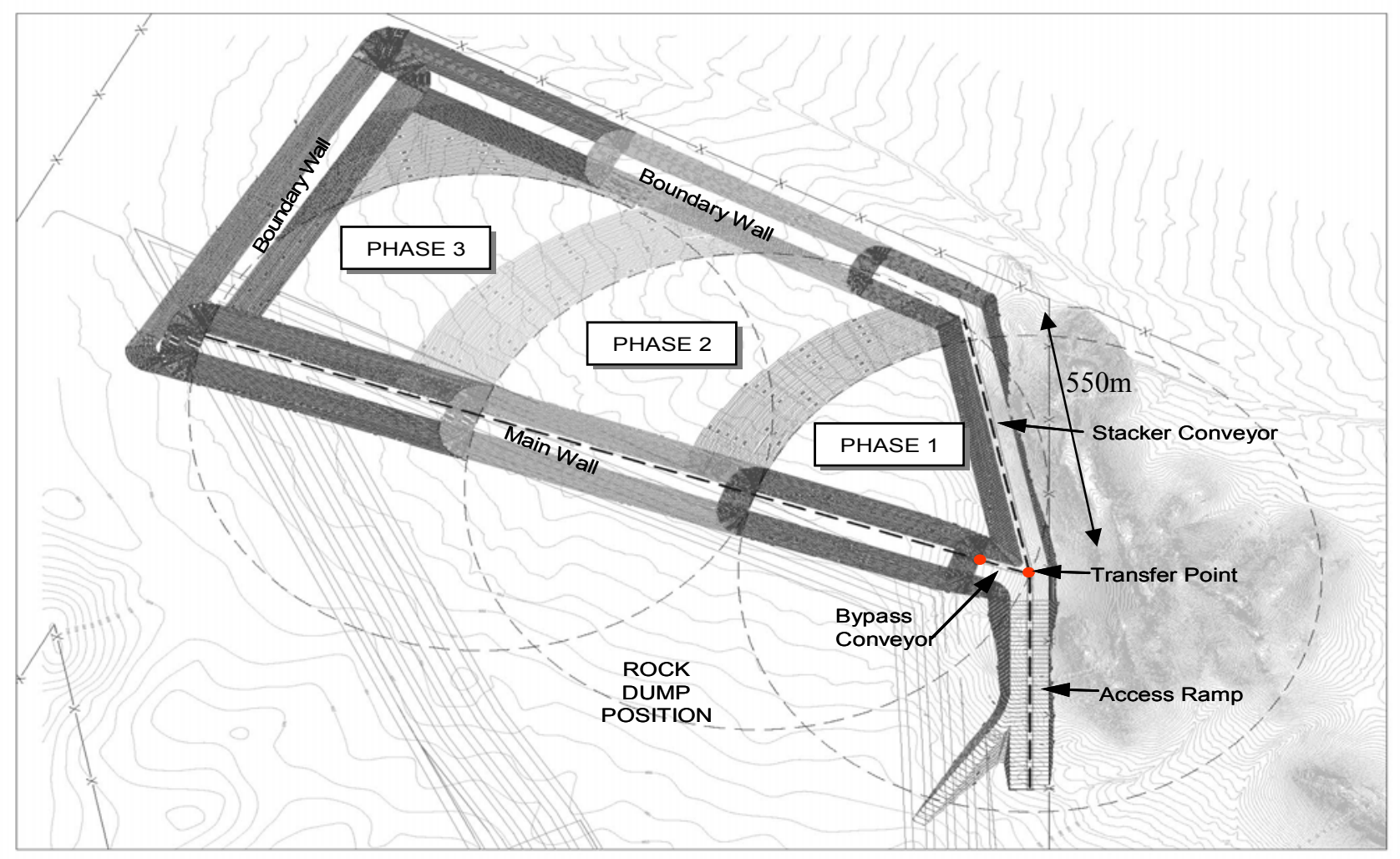

\section{Figure 2 Phased design layout of pivoting tailings stacker system}

\subsection{Key design issues}

In the relatively new field of large volume tailings dewatering, moisture content or density control has been a key issue or in some cases a "failing". While the installed equipment may achieve its design moisture content, at times it has in practice often been difficult to continuously operate such equipment at the required set points. While it should be possible to achieve better control with filtration than with thickeners, the implications of poor moisture content control on conveying a "sloppy" or "sticky" cake could stop the plant. This raised a number of design risk questions including:

- How should the transfer point chutes be designed and what belt cleaning devices are required? 
- What bearing capacity would the tailings provide for the stacker conveyor?

- To what angle would the tailings cake flow and would the dump be stable?

- What would be the frequency of advance (rotation) of the stacker conveyor?

- To what specifications should the tailings platform be constructed and to what tolerances should the stacker conveyor be built to accommodate the frequent moves?

\subsubsection{Transfer point design}

The chutes were to be made as steep as possible with maximised openings. They were to be ceramic tile lined to reduce friction and wear rates. The chutes were to be shaped to have minimal impact zone to minimise tailings sticking to the walls.

It was envisaged that the tailings would stick to the belt, particularly at high moisture contents. To ensure that the belt was effectively cleaned, a double scraper system was required. A spray belt cleaning system was not entertained because of water wastage. The return belt was to be turned over on the $3 \mathrm{~km}$ overland section to minimise spillage.

Moving head transfers were designed to discharge off the emergency and by-pass conveyors.

\subsubsection{Tailings bearing capacity}

The tailings testwork did not provide definitive answers on consolidation drying and bearing capacity development. It was envisaged that a D9 or equivalent bull-dozer would be used to spread the tailings at the face. Such a tracked machine has a bearing pressure of $90 \mathrm{kPa}$. Based on the assumption that a dozer could work safely at the dump edge, it was agreed that $90 \mathrm{kPa}$ should be used as the maximum allowable pressure beneath the tripper and spreader equipment. This load would be transferred through the rails to the sleepers resting on the tailings.

Since achieving a bearing capacity of $90 \mathrm{kPa}$ remained an assumption, back-up plans such as high flotation tracks, importing a pioneer layer, laying a geotextile layer on the tailings and adding salt were considered to improve the bearing capacity. In addition, the spreader was allowed to rotate through 270 degrees and backstack behind the conveyor, delaying each move and allowing more time for consolidation.

\subsubsection{Tailings beach angle}

The laboratory tests had not provided sufficient data for predicting the beach angle of the cake on a large scale, and even with vibration did not exhibit high slump or release water. At the Anglo Base Metals mine using the pivot conveyor system, the tailings flowed at a slope angle of 6 to 8 degrees. In comparison, this tailings has a moisture content of $20 \%$, and is a much coarser material. From observations of fine diamond tailings dump behaviour, it was expected that the tailings would flow to a composite angle, simplistically made up of an upper slope of 30 degrees and a lower slope of 15 degrees. 
This raised questions of stability, which required knowledge of the phreatic level. High moisture content would affect both the slope angle and phreatic level. The main concern was that if the tailings did stand up at 30 degrees, sudden failure could occur, especially when the stacker conveyor is advanced close to the face. To reduce the risk of instability, a deposition plan was proposed that deposited the majority of the tailings at the thick section of the wedge first allowing maximum time for drying in the area over which the largest advance would take place. The tripper and spreader would also move backwards and forwards, depositing thin layers, maximising time for drying.

\subsubsection{Frequency of advance}

Modelling of the dump made it possible to calculate the average time between moves. The average rate worked out at 3 months which was considered acceptable. However, this time would reduce considerably when approaching the end of a rotation cycle as the tailings would flow up against the main wall. There would come a point when the frequency was too great and relocation of the stacker would have to take place.

While a move takes place, the by-pass conveyor would be required. A flexible system comprising a $100 \mathrm{~m}$ conveyor and $3 \times 10 \mathrm{~m}$ long grasshopper spreaders was considered a suitable system. These could be moved by bull-dozer to provide additional capacity.

\subsubsection{Conveyor tolerances and tailings platform specifications}

Since the $40 \mathrm{~m}$ high tailings dump was expected to exhibit total settlement of up to $2 \mathrm{~m}$, the conveyor system would need to be flexible to accommodate these movements. It could not be designed as a railway line. The tripper and spreader would also need to withstand high wind loads, including an auto-trip switch to shut down and slew the boom to face in the correct direction to prevent toppling of the counter-weight system.

For each move a platform would need to be prepared that would require levelling with survey assistance. The tripper would then drive to the pivot end. The sleepers, rails and conveyor modules would be dragged forward by a bull-dozer in $0.5 \mathrm{~m}$ increments, with the dozer running parallel to the conveyor and using a lifting device attached to the rails. On completion of the move, the sleepers would be aligned vertically and horizontally within acceptable tolerances before the tripper could operate normally again.

\section{TAILINGS DISPOSAL - EARLY OPERATION}

The tailings disposal system has been operating since August 2003. Initially the emergency stockpile area was used extensively since the cake moisture fell outside of the $<44 \%$ specification. In a reasonably short period of time the operation of belt filtration system was under control, and moisture contents as low as $36 \%$ were achieved, with average moisture contents of the order of $40 \%$. This allowed full commissioning of the overland conveyors and deposition system. 


\subsection{Short-comings of conveyor system}

Four aspects of the conveyor system were found to have short-comings:

- The main conveyor receiving tailings from the reload facility was overloaded by the batch process installed, resulting in double-handling of the tailings by trucking away at high cost.

- The tailings stuck to the ceramic chute linings regularly blocking them. They were relined with a lower friction material (solidor).

- The transfer points have to be modified due to spillage and resultant poor belt alignment.

- The grasshopper spreaders on the by-pass conveyor did not provide adequate capacity ( $2 \mathrm{hrs}$ as opposed to 2 days).

Typically wet cake was deposited on the emergency stockpile but above a height of 5 to $8 \mathrm{~m}$ it slumped. On a few occasions the nearby conveyor was damaged and a bund wall was required to protect it.

The design of the first conveyor onto which the filter cake drops from the filtration plant is critical to the operation. If this stops, the plant stops. This conveyor is more difficult to maintain because of its location and the fact that no by-pass exists. This places a high priority on belt filter control, since even one out of six operating badly can cause chute blockages.

\subsection{Observations at the tailings dump}

On the tailings dump, the following initial observations were made:

- The tailings developed a composite slope angle, that slowly flattened with time, with the upper slope varying from 30 to 16 degrees, and the lower slope averaging 5 degrees, see Figure 3.

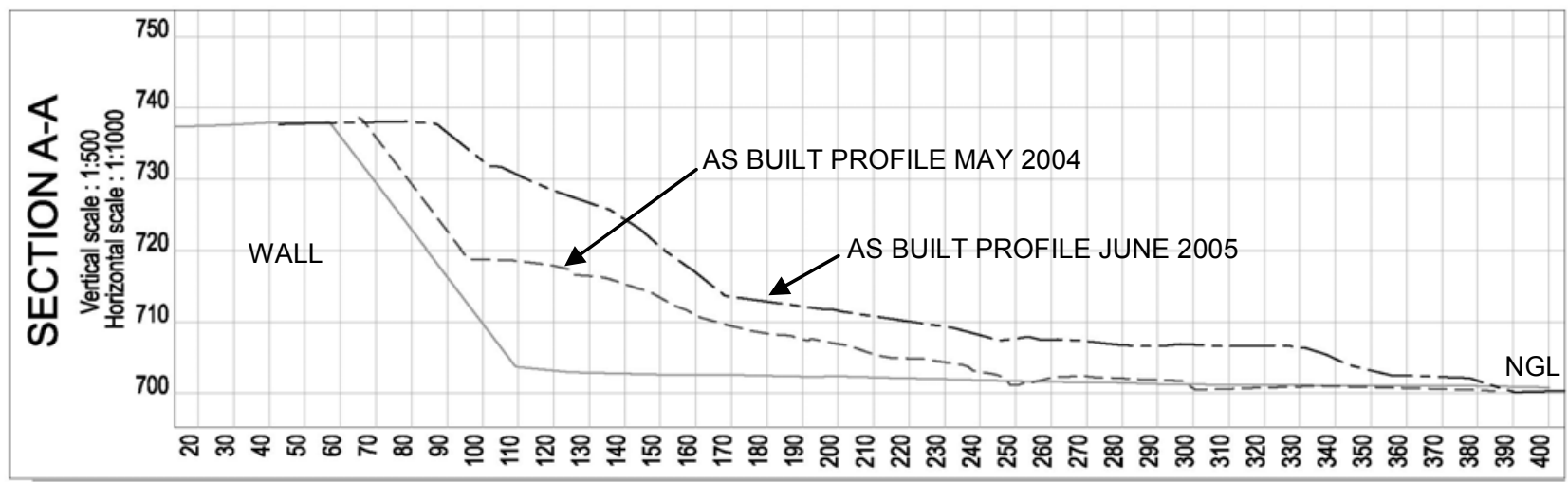

Figure 3 Composite tailings beach profile changing with time

- The length of the "mud" flow to the toe (up to $300 \mathrm{~m}$ ) was dependant on the moisture content.

- $10 \mathrm{~m}$ high waste rock walls were required to control the toe flow. 
- Stacking in thin layers resulted in a steep upper slope and had the potential for sudden failure.

- Continuous deposition in one place resulted in the tailings flowing out like lava with minimal hangup and hence minimal stability concerns, giving a larger evaporative area.

- Small pockets of free water formed in low spots on the dump, especially after prolonged deposition of high moisture content cake.

The development of a long tailings beach may delay conveyor advances initially, but may increase the frequency of future advances.

\subsection{Bearing capacity}

It was possible to walk on the tailings within a few days of deposition, albeit that a thin dry crust (desiccated salt crust) had developed and little moisture loss had taken place below. Dozing trials indicated that within three weeks of deposition, the tailings could carry the dozer, although the risk of the machine getting stuck was high and operator training was required. A simple indicator test was developed that the dozer operator could use to test tailings before working on it. A hand held $1 \mathrm{~m}$ long dynamic cone penetrometer yielded measurements of resistance to penetration that could be correlated by means of pate jacking tests to bearing capacity. The tailings on top of the dump was found to achieve values exceeding the required $100 \mathrm{kPa}$ within short periods of time and the dozer could push heaps over the edge. It was shown that these heaps should not be allowed to exceed $2 \mathrm{~m}$ above the crest level since drying of higher heaps did not occur sufficiently to allow safe dozing.

\subsection{Conveyor moves and frequency}

The higher than expected bearing capacities made it possible to form a platform prematurely and undertake a "practice" move. A precautionary approach was used to form the platform, importing gravel, compacting and levelling. For the $2^{\text {nd }}$ move ( 5 months later), less gravel was imported to start optimising the process. The first conveyor move took five days to complete, whilst the second took two days. Some settlement cracks have been observed along the conveyor structure, and a survey system has been established to monitor displacements.

From modelling work a rotational move frequency of 4 months on average was calculated. However, a rethink of the pivot advance system realised that a face advance system could be implemented on the existing system, with little modification. This should decrease the move frequency and realise a more cost-effective disposal system.

\section{CONCLUSIONS}

The trade-off study of alternatives followed an integrated and systems approach to determining the best disposal system and is considered good practice. 
The selection of a conveyor versus hydraulic disposal system for filtered tailings has been justified in terms of water conservation, other reduced environmental impacts and a more cost effective disposal system. This is despite the "potters clay" consistency of the cake at $40 \%$ moisture content.

The main concern of variable moisture control has been effectively mitigated by good filter plant management. At times of high moisture and high tonnage, chute blockages do occur that stop the plant.

The selection of a pivot advancing stacker conveyor system has been found to be less practical than a face advance system. The conversion is currently being implemented at low cost and should reduce advance frequency and obviate the need for the major stacker conveyor relocations than would otherwise be necessary.

Extended deposition of tailings at one point is preferred to stacking of the tailings in thin layers since it decreases potential instability near the face.

It is essential to have a good emergency and by-pass conveyor system, including a functional reload facility.

Good maintenance has been found to be more critical on this conveyor system than for other conveyor systems due to the behaviour of the tailings.

\section{ACKNOWLEDGEMENTS}

Anglo Base Metals project team input during feasibility study and design.

Bateman Engineering during feasibility study and SPJV members for conveyor designs.

Skorpion Zinc Mine officials for their operational input and experiences.

\section{REFERENCES}

Anglo American Technical Services (2000) Skorpion Zinc project - feasibility study, tailings disposal system, Report No. CED/025/2000, April, Anglo Base Metals.

Jones and Wagener Consulting Engineers (1998) Tailings disposal facility, Skorpion zinc study, Bateman Minerals and Industrial Ltd, Report Numbers G46/98/6698 \& G38/99/6698, March and November.

Multiple Accounts Analysis (1999) A management decision theory tool for multiple stakeholder decision-making and conflict resolution, Mining and Geoscience Tool Catalogue, Edumine, www.edumine.com. 